\title{
THE METALLURGY OF THE \\ COLOURED CARAT GOLD AlLOYS
}

\author{
William S. Rapson
}

Despite the fact that this topic
was last reviewed in this Bulletin in 1978,
there was until 1989 little of significance
reported in the scientific and technical literature
to justify an updating of the position.
The reporting in that year [1] of the 990 gold-titanium alloy
as suitable for fabrication of gold jewellery of
this fineness (23.76 carat) has changed this position.
This further review therefore consists essentially of
two parts:
In the first,
the conventional coloured carat gold alloys based on 120
Au-Ag-Cu and Au-Ag-Cu-Zn systems are discussed. The
treatment follows that of McDonald and Sistare [2]
and is largely a resumé of their excellent review
which has features that well merit being brought to
the attention of readers again.
In the second,
goldsmiths and manufacturers.
the new 990 Au-Ti alloy is discussed
with special reference to its potential for use by




\section{The Coloured}

\section{Gold Alloys Based}

on the Au-Ag-Cu

and Au-Ag-Cu-Zn Systems

\section{Alloys Based}

\section{on the Au-Ag-Cu System}

The metallurgy of the coloured gold alloys was reviewed by A.S. McDonald and G.H. Sistare of Handy and Harman (Fairfield, Conn., U.S.A.) in 1978 [2]. They considered first the alloys of the $\mathrm{Au}-\mathrm{Ag}$-Cu system, from which all the carat gold alloys in this class inherit certain fundamental metallurgical characteristics. They detailed these and demonstrated (see below) how the introduction of zinc in the amounts (up to $15 \%$ ) in which it may be present in Au-Ag-Cu-Zn carat gold alloys modifies them. The very important contribution of these authors was their analysis of the properties of $\mathrm{Au}-\mathrm{Ag}-\mathrm{Cu}$ alloys in terms of three quasi-binary vertical sections (Figure 1) of the ternary diagram at constant gold contents corresponding to caratages of 18,14 and 10 respectively. (The section for a caratage of 9 may be taken to be very similar to that for the caratage of 10 ).

Instead, however, of plotting the silver concentrations on the abscissae, to designate alloy composition, they used a parameter $\mathrm{Ag}^{\prime}$, which was defined as:

$$
\mathrm{Ag}^{\prime}=\frac{\mathrm{Ag}(\mathrm{wt} . \%)}{\mathrm{Ag}(\mathrm{wt} . \%)+\mathrm{Cu}(\mathrm{wt} . \%)} \times 100 \%
$$

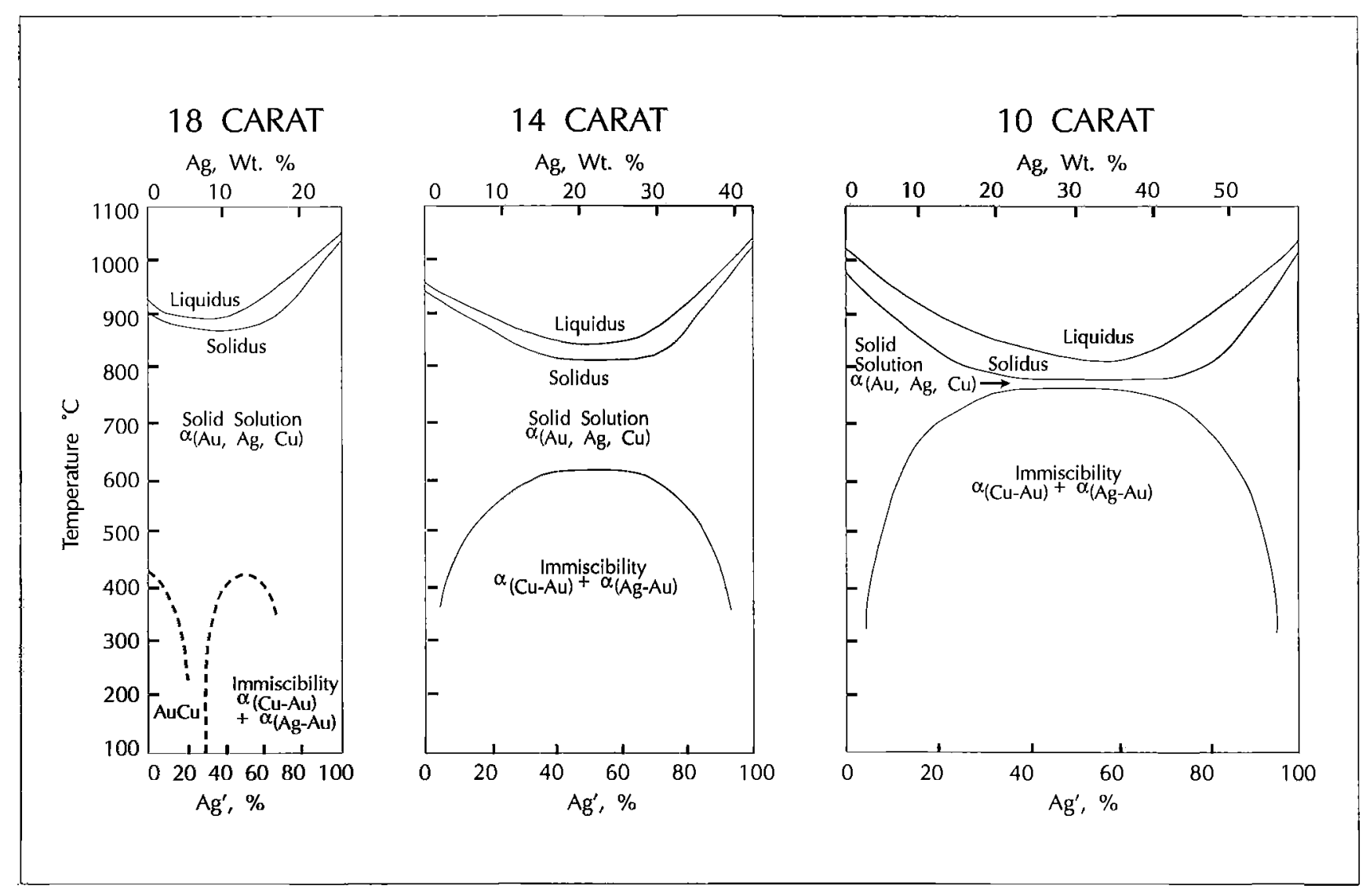

Figure 1

Schematic quasi-binary sections at constant caratage of the gold-silver-copper ternary phase diagram. The parameter $A g^{\prime}$ is defined in the text. 


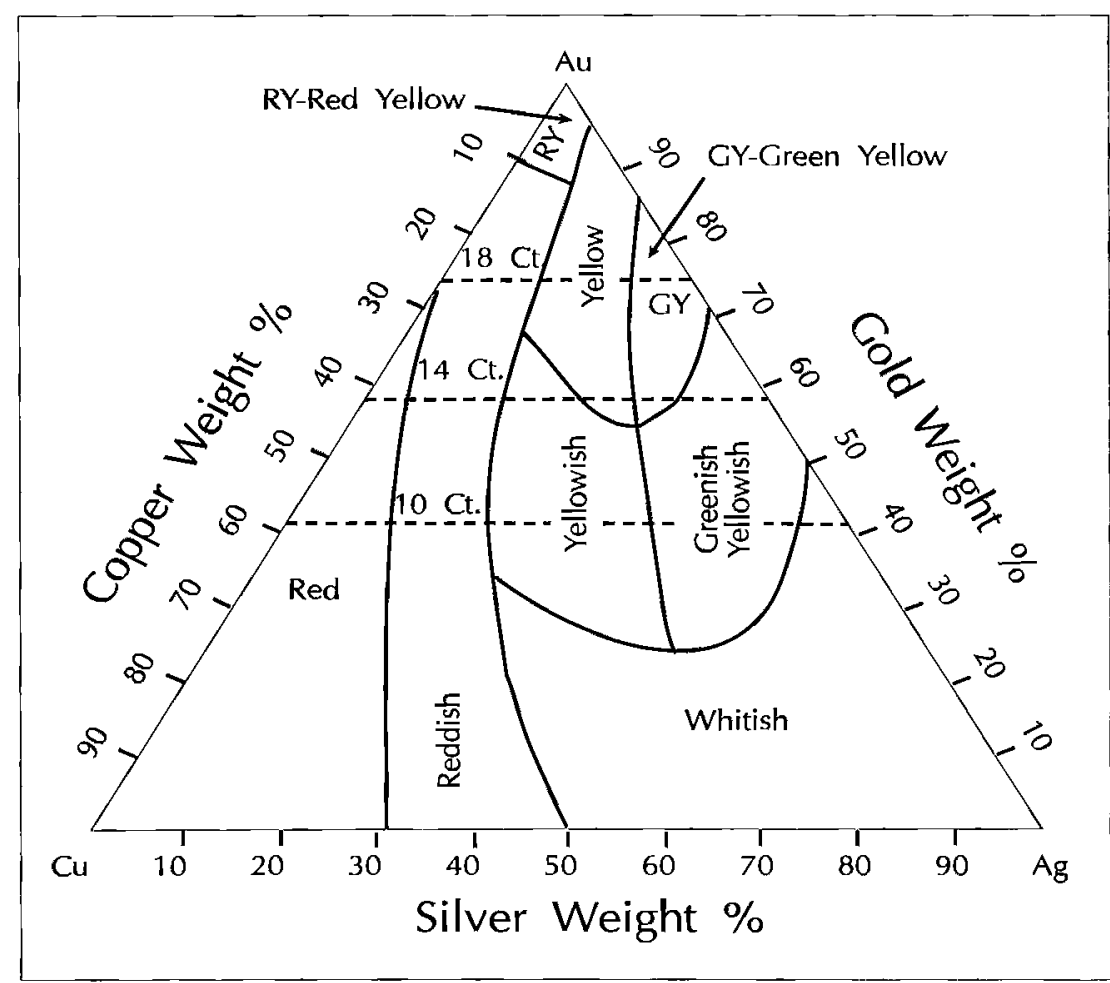

rich alloys. These type II alloys are moderately soft in the annealed condition but are age-hardenable on heat treatment.

- Type III, in which $\mathrm{Ag}^{\prime}$ is in the range from about 25 to $75 \%$. Alloys of this type are also homogeneous solid solutions above the immiscibility gap, but if slowly cooled to equilibrium room temperature, they decompose into both $\alpha(\mathrm{Ag}-\mathrm{Au})$ and $\alpha(\mathrm{Cu}-\mathrm{Au})$. Alloys of this type are hard in the annealed condition. They harden significantly on air cooling and are difficult to quench. They are age-hardenable

Figure 2

Relationship between the colour and composition of gold-silver-copper alloys. After [3].

The authors then proceeded to show that Au-Ag$\mathrm{Cu}$ (and $\mathrm{Au}-\mathrm{Ag}-\mathrm{Cu}-\mathrm{Zn}$ ) alloys can be logically classified and discussed in terms of only two parameters, namely their caratage and $\mathrm{Ag}^{\prime}$.

Based on the solid-state immiscibility gap and on the value of $\mathrm{Ag}^{\prime}$, three types of alloys were distinguished, namely:

- Type $\mathrm{I}$, in which $\mathrm{Ag}^{\prime}$ ranges from 0 to about $10 \%$ or from about 90 to $100 \%$. Such alloys, as will be seen from Figure 1, exist as homogeneous solid solutions at all temperatures below the melting point. They are soft in the annealed condition and are not hardenable.

- Type II, in which $\mathrm{Ag}^{\prime}$ is in the range from about 10 to $25 \%$ or 75 to $90 \%$. These alloys exist as homogeneous solid solutions at temperatures above the immiscibility gap, but if they are slowly cooled to equilibrium at room temperature $\alpha(\mathrm{Ag}-\mathrm{Au})$ will precipitate in copper-rich alloys and $\alpha(\mathrm{Cu}-\mathrm{Au})$ in silver-

\section{Alloys Based on the Au-Ag-Cu-Zn System}

The relationship between the colour and composition of $\mathrm{Au}-\mathrm{Ag}-\mathrm{Cu}$ alloys is illustrated in Figure 2 [3]. The colours range from gold-yellow near the gold-rich corner, to silver-white near the silver-rich corner, to copper-red. This last colour dominates not only the copper-rich corner, but also most of the copper-rich and gold-rich side of the diagram. The fact that alloys in these red and reddish areas can be made yellowish by additions of zinc is exploited in practice. These additions, which may be up to $15 \mathrm{wt} . \%$, tend to reduce the volume of solid state immiscibility in the ternary phase diagram [4]. They cause a narrowing and a reduction in height of the two-phase area on each of the constant gold content sections of the ternary diagrams as presented in Figure 1. The Au-Ag-Cu-Zn carat gold alloys tend to be softer than the corresponding types of Au$\mathrm{Ag}-\mathrm{Cu}$ alloys in both the annealed and precipitation hardened states. 


\section{Commercial Coloured \\ Gold Alloys Based on \\ the $\mathrm{Au}-\mathrm{Ag}-\mathrm{Cu}$ and \\ $\mathrm{Au}-\mathrm{Ag}-\mathrm{Cu}-\mathrm{Zn}$ Systems}

These can now with advantage be discussed in terms of the McDonald and Sistare classification into types I, II and III described above.

\section{Carat \\ Coloured Alloys}

Since useful 14 carat alloys can be made at all values of $\mathrm{Ag}^{\prime}$, as is illustrated in Table 1, these will be discussed first. With all 14 carat alloys (see Figure 1), the immiscibility gap is well developed, but there is a substantial temperature range between the top of the gap and the solidus over which the alloys are homogeneous. This permits alloys at all values of $\mathrm{Ag}^{\prime}$ to be homogenized at elevated temperatures and to be quenched as homogeneous solid solutions at room temperature.

The hardness of these quenched solid solutions varies with $\mathrm{Ag}^{\prime}$. It is lowest for type I alloys, increases throughout the $\mathrm{Ag}^{\prime}$ range of type II alloys, and is high in type III alloys. The Ag-rich type I and II alloys are somewhat softer than the Cu-rich type I and II alloys.

The workability of the alloys is related to their hardness range (Table 2). Type I alloys are the most easily worked, but they do not age-harden and are hardenable only by cold working. Type II alloys are workable in the annealed state and can be precipitation hardened after fabrication. Type III alloys are the hardest and most difficult to work. They require careful quenching, and if quenching is not done rapidly and effectively, decomposition of their solid solutions and age-hardening will occur.

Annealing of the alloys should be possible (see Figure 1) at $650^{\circ} \mathrm{C}$ and this is the case. All the alloys in this class can be recrystallized and homogenized at this temperature. In practice, however, with wrought material under-annealing may lead to survival of a directionality of properties in the cold worked and subsequently annealed alloys, while over-annealing will result in excessive grain growth and the risk of orange-peel effects arising in subsequent working. With castings being solution annealed for subsequent precipitation hardening, when the only objective is to put the alloy in solid solution form, higher temperatures and longer times may be used. In general, the annealing temperature recommended can be varied with $\mathrm{Ag}^{\prime}$, being lowest for

Table 1

Composition of Some 14 Carat Gold Alloys

Commonly Used for Jewellery Manufacture in North America

\begin{tabular}{|c|c|c|c|c|c|c|}
\hline $\begin{array}{l}\text { Alloy } \\
\text { code }\end{array}$ & $\mathrm{Au}$ & $\mathrm{Ag}$ & $\begin{array}{c}\mathrm{Cu} \\
\mathrm{Cu}\end{array}$ & $\mathrm{Zn}$ & $\begin{array}{l}\mathrm{Ag}^{\prime} \\
\%\end{array}$ & $\begin{array}{l}\text { Alloy } \\
\text { type }\end{array}$ \\
\hline 110 & 58.3 & 4.6 & 36.9 & 0.2 & 11 & I \\
\hline 220 & 58.3 & 9.1 & 32.4 & 0.2 & 22 & II \\
\hline 310 & 58.3 & 12.9 & 28.6 & 0.2 & 31 & III \\
\hline 400 & 58.3 & 16.5 & 25.0 & 0.2 & 40 & III \\
\hline 600 & 58.3 & 24.8 & 16.8 & 0.2 & 60 & III \\
\hline 750 & 58.3 & 31.0 & 10.5 & 0.2 & 75 & III \\
\hline 780 & 58.3 & 32.5 & 9.0 & 0.2 & 78 & II \\
\hline 850 & 58.3 & 35.0 & 6.5 & 0.2 & 84 & II \\
\hline 116 & 58.3 & 4.0 & 31.3 & 6.4 & 11 & I \\
\hline 224 & 58.3 & 8.3 & 29.2 & 4.1 & 22 & II \\
\hline
\end{tabular}


type I, intermediate for type II and highest for type III alloys.

In Figure 3, the hardness values after annealing and water quenching and the maximum hardness values after heat treatment for the alloys listed in Table I, as plotted by McDonald and Sistare against $\mathrm{Ag}^{\prime}$ are presented.

A comparison of this with the 14 carat section in Figure 1 demonstrates how well the concept of $\mathrm{Ag}^{\prime} \mathrm{im}$ poses order on 14 carat AuAg-Cu jewellery alloys.

The hardness values for alloys 110,116 and 224 also
Table 2

Rockwell Superficial Hardness (HR45T) of Some 14 Carat Coloured Gold Alloys as Annealed and in the Precipitation Hardened Conditions

\begin{tabular}{|c|c|c|c|c|}
\hline Alloy & $\begin{array}{l}\text { Annealed } \\
\text { Condition }\end{array}$ & \multicolumn{3}{|c|}{$\begin{array}{c}\text { Hardened condition after annealing and quenching } \\
\text { HR } 45 T \\
\text { Hardening temperature }\end{array}$} \\
\hline code & HR45T & $205^{\circ} \mathrm{C}$ & $260^{\circ} \mathrm{C}$ & $315^{\circ} \mathrm{C}$ \\
\hline 110 & $38-40$ & $42-48$ & $45-46$ & $42-43$ \\
\hline 220 & $47-51$ & $68-69$ & $75-76$ & $75-76$ \\
\hline 310 & $53-63$ & $73-74$ & $75-76$ & $75-76$ \\
\hline 400 & $58-71$ & $70-74$ & $71-73$ & $74-75$ \\
\hline 600 & $58-69$ & $70-71$ & $71-72$ & $74-75$ \\
\hline 750 & $49-68$ & & $68-69$ & $71-72$ \\
\hline 790 & $43-53$ & & $65-66$ & $68-69$ \\
\hline 850 & $34-38$ & & $60-62$ & $64-65$ \\
\hline 116 & $25-28$ & $32-33$ & $27-28$ & $33-36$ \\
\hline 224 & $40-43$ & $65-67$ & $71-72$ & $60-61$ \\
\hline \multicolumn{5}{|c|}{$\begin{array}{l}\text { Specimens: } 50 \times 13 \times 0.8 \mathrm{~mm} \text {, cold rolled } 50 \% \text { prior to annealing. Annealing time and Temperature: } \\
30 \mathrm{~min} \text { ar } 650^{\circ} \mathrm{C} \text {. Hardening rime: } 2-4 \mathrm{~h} \text {. }\end{array}$} \\
\hline
\end{tabular}

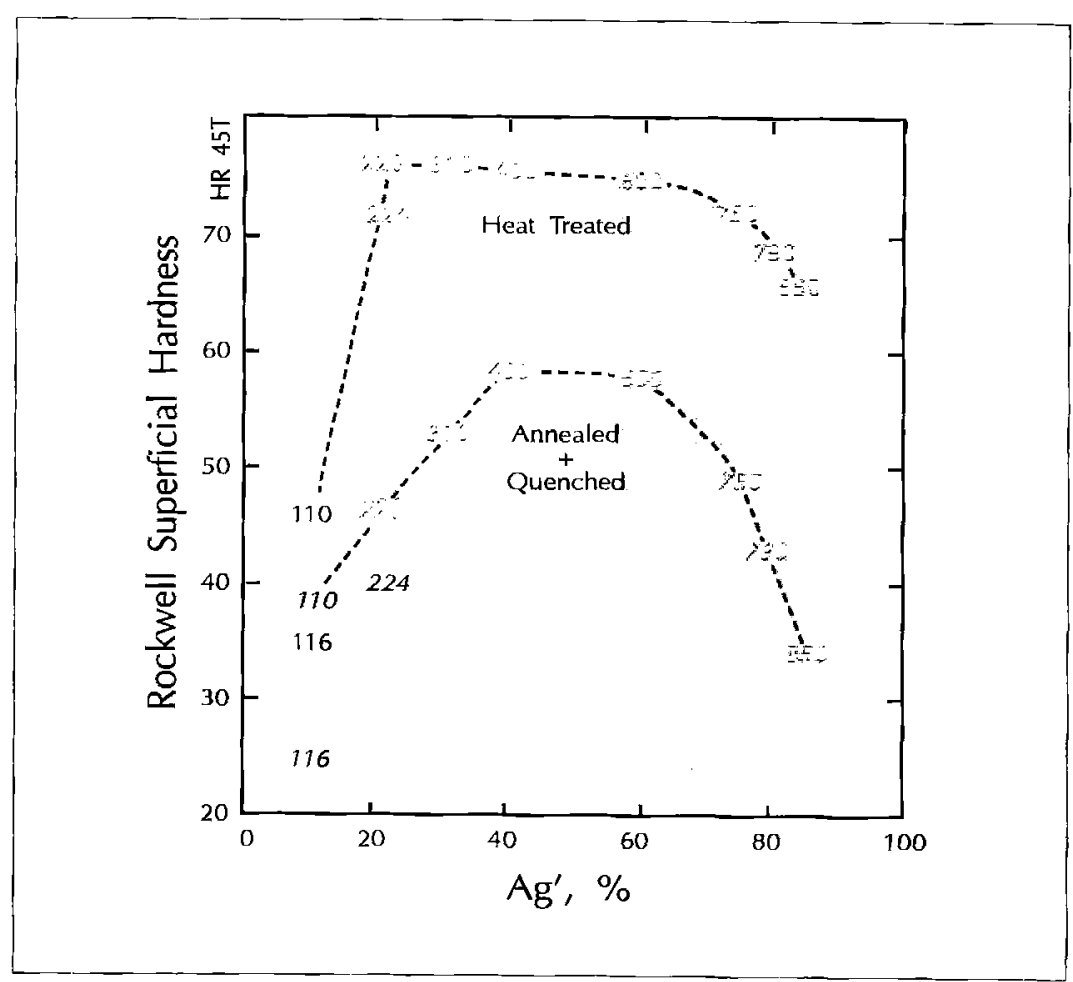

Figure 3

Rockwell superficial hardness (HR45T) of 14 carat commercial gold alloys in the annealed and quenched and the heat treated conditions as a function of $\mathrm{Ag}^{\prime}$. The alloys are coded as in Tables 1 and 2 . illustrate the softening effect of zinc additions to these alloys previously referred to.

\section{Carat \\ Coloured Alloys}

From Figure 1 it will be seen that the immiscibility field is broader and higher for 10 carat than it is for 14 carat alloys. In general, however, it will be noted that 10 and 14 carat alloys with $\mathrm{Ag}^{\prime}$ values in the type I, II and III ranges of composition respectively occupy corresponding positions in the 10 and 14 carat quasi-binary sections of the $\mathrm{Au}-\mathrm{Ag}-\mathrm{Cu}$ phase diagram (see Figure 1). It follows that there should be a correspondence between the metallurgical properties of 10 and 14 carat alloys with the same $\mathrm{Ag}^{\prime}$ values, and with certain exceptions, this is the case. Such alloys have been described as having 'associated' alloys compositions.

One source of exceptions can be illustrated by reference to Figure 4, which 
is a projection on the room tenperature plane of the $\mathrm{Au}-\mathrm{Ag}-\mathrm{Cu}$ phase diagram of some isothermal solid state boundaries of the immiscibility field. 'Associated' alloy compositions characterized by a particular value of $\mathrm{Ag}^{\prime}$ all fall on a line which may be imagined as joining the gold comer of the diagram to a point on the $\mathrm{Ag}-\mathrm{Cu}$ base corresponding to this value of $\mathrm{Ag}^{\prime}$. If such a line falls outside the immiscibility gap at 14 and 10 carat levels of gold content, then the properties of the associated alloys will be the same at both caratages. This means that they will be relatively soft homogeneous solid solutions and not age-hardenable. They will both be typical type I alloys. If, however, the constant $\mathrm{Ag}^{\prime}$ line falls inside the immiscibility gap at both 10 and 14 carat compositions, it will be further inside this gap in the case of the 10 carat alloy than in the case of the 14 carat alloy, because of the greater width of the gap at the 10 carat level (see Figure 1).

The effect of this depends on

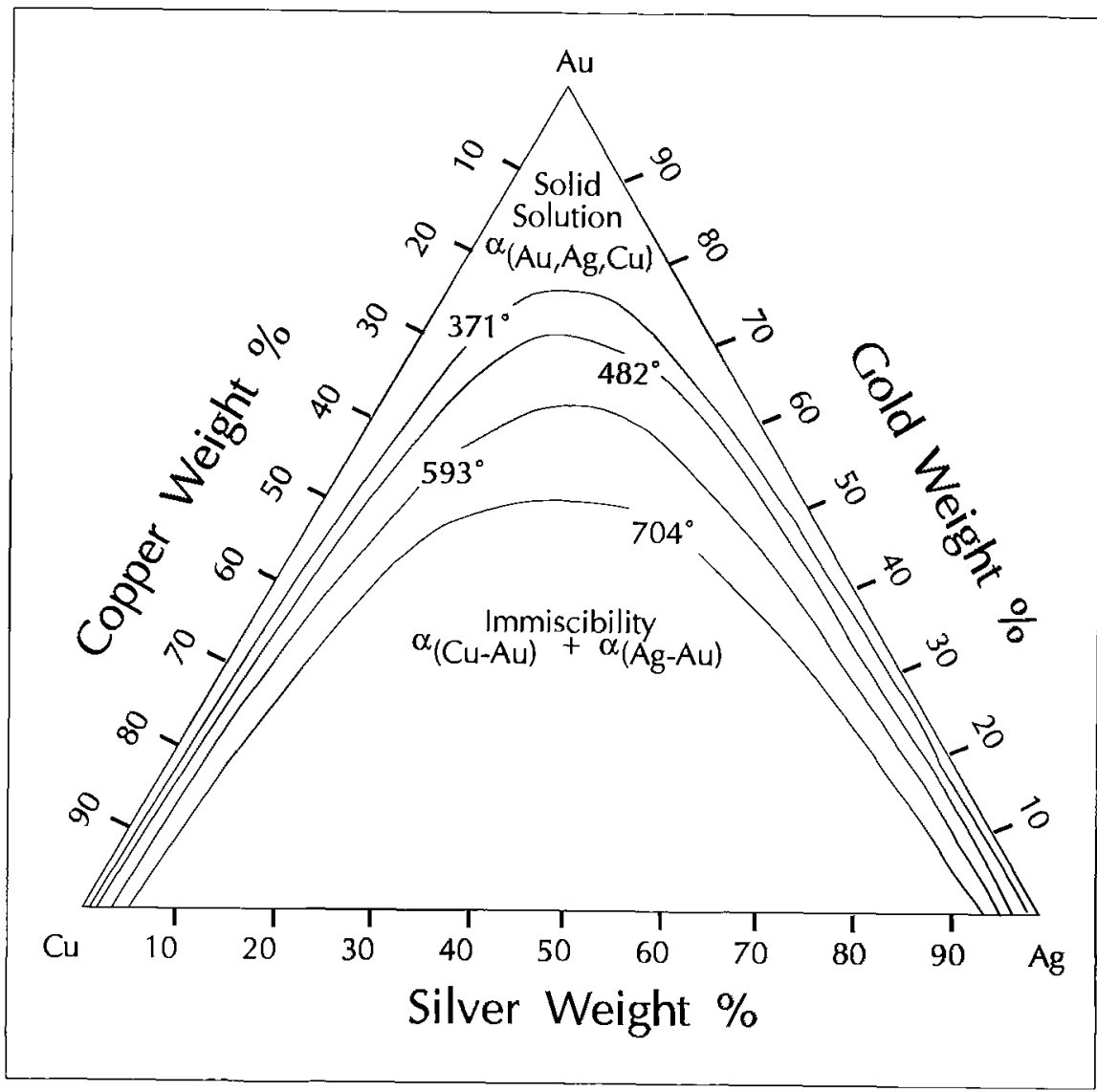

Figure 4

Projection on the room temperature plane of the gold-silver-copper ternary phase diagram of some isothermal solid state boundaries of the immiscibility field. After [25]. the value of $\mathrm{Ag}^{\prime}$ and therefore on the type of the alloy. Type III alloys which are well inside the immiscibility gap at both caratages tend to have similar properties at both caratages. However, at 10 carat they are harder and more difficult to anneal and quench than at 14 carat and find little application. In the case of 'associated' type II alloys marked differences call occur. Thus an alloy just inside the immiscibility field at 14 carat, will be capable of only moderate precipitating hardening, whereas its 'associated' 10 carat alloy may be well inside the field and precipitation harden to a significant degree. Such displacements relative to the immiscibility field will also give rise to differences in other characteristics of the associated alloys such as solutionizing, processing and optimum precipitation temperatures, optimum ageing time and susceptibility to overageing and softening.

A second reason for exceptions in respect of the expected correspondence between 'associated' 14 and 10 carat alloys may be the effect of the zinc added to many of these alloys. This tends to reduce the volume of the immiscibility field and moreover the absolute zinc content increases in the 10 carat alloys in which the same relative proportions of silver, copper and zinc are maintained.

In spite of these exceptions, the extent of the correspondence between the expected properties of 10 carat alloys and those of their associated 14 carat alloys is remarkable. For example the following are the compositions of three typical commercial 10 carat gold jewellery alloys which have the same $\mathrm{Ag}^{\prime}$ values as the 14 carat alloys 116, 224 and 850 listed in Table 1: 


\begin{tabular}{ccccccc} 
Code & $\mathrm{Au}$ & $\mathrm{Ag}$ & $\mathrm{Cu}$ & $\mathrm{Zn}$ & $\mathrm{Ag}^{\prime} \%$ & Type \\
\hline 119 & 41.7 & 5.50 & 43.8 & 9.0 & 11 & $\mathrm{I}$ \\
226 & 41.7 & 11.70 & 40.8 & 5.8 & 22 & $\mathrm{I}$ \\
840 & 41.7 & 48.90 & 9.05 & 0.35 & 84 & II
\end{tabular}

The 'associated' type I 14 and 10 carat alloys (Codes 116 and 119) have mechanical properties so nearly the same that they can be processed in essentially the same way. The type II 14 and 10 carat alloys, however, show significant differences in behaviour. These can be attributed in the case of the one pair (14 carat code 224 and 10 carat code 226) to the fact that the 14 carat alloy falls only just inside the immiscibility field with the result that the 'associated' 10 carat alloy is well within this field, with the consequences described above. In the case of the other pair (14 carat code 850 and 10 carat code 840) the differences are due to the net effects of shifts in the solid solution boundary in converting from 14 carat to 10 carat on the one hand and on the other hand to the reduced volume of the immiscibility field resulting from the increase in absolute zinc content of the 10 carat alloy as compared with that of its 'associated' 14 carat alloy.

\section{Carat}

\section{Coloured Alloys}

The concept of alloy types, which is so useful in discussing 14 carat and 10 carat alloys is much less useful with 18 carat alloys. Thus the immiscibility field occupies a much smaller area of the solid state field in these alloys than it does in the alloys of lower caratages. Moreover the Au-Cu ordered phase of the Au-Cu binary system occupies part of this field (Figure 4 and reference). One effect of this is that, for example, a copper-rich alloy in the $\mathrm{Ag}^{\prime}$ range of composition corresponding to type I, and which would be soft and not age-hardenable at 10 and 14 carat, is hardenable at 18 carat due to the influence of the $\mathrm{Au}-\mathrm{Cu}$ ordered phase. Another effect is that alloys in the $\mathrm{Ag}^{\prime}$ range corresponding to type III, which are all hard at 10 and 14 carat, are only moderately hard and age-hardenable at 18 carat, because of the restricted area of the immiscibility field. They tend to resemble type II 14 carat and 10 carat alloys. Above an $\mathrm{Ag}^{\prime}$ value of $75 \%$, moreover, 18 carat alloys are soft and nonhardenable.

\section{Coloured Alloys \\ of Caratages Greater than 18}

Above $18 \mathrm{carat}$, the concept of types is not applicable. In this range, $\mathrm{Au}-\mathrm{Ag}-\mathrm{Cu}$ alloys, both annealed and heat treated, are progressively softer with increasing gold content. Their properties approach those of 24 carat or pure gold, and they find little application except in the production of gold coins and medallions, for which alloys of fineness 900 ( 21.6 carat) and 916.66 ( 22 carat) are widely used. Because of their relative softness and their relative susceptibility to scratching and wear, they have not been greatly used in fabrication of jewellery, other than wedding rings. It is because of these facts that the introduction of the new 990 gold-titanium alloy, with a caratage of 23.76 , is so significant.

\section{Alloy Data in Respect of Commercial Coloured Carat Gold Alloys Based on the Au-Ag-Cu and $A u-A g-C u-Z n$ Systems}

As a result of cooperation between the International Gold Corporation Ltd., Degussa AG, Johnson Matthey Metals Ltd. and Métaux Précieux SA Metalor, technical data in regard to a number of standard coloured carat gold alloys widely used in jewellery fabrication, especially in Europe, have become available in recent years. The alloys for which such data are available are the following:

Alloy * Designation Reference

23.76 carat

Au 990-Ti 10

22 carat

$\mathrm{Au}$ 917-Ag 32-Cu 51

Au 917-Ag 55-Cu 28

18 carat

Au 750-Ag 125-Cu 125

Au 750-Ag 160-Cu 90

$\mathrm{Au} 750-\mathrm{Ag} 90-\mathrm{Cu} 160$

Au 750-Ag 45-Cu 205

14 carat

Au 585-Ag 265-Cu 150

Au 585-Ag 205-Cu 210

Au 585-Ag 90-Cu 325

Au 585-Ag 100-(Cu-Zn) 315

Au 585-Ag 300-Cu 115
22 LS (dark yellow) 12

22 LS (yellow) 14

$750 \mathrm{Y}-3$ (yellow) 5

750 Y-2 (pale yellow) 6

$750 \mathrm{Y}-4$ (pink) 7

Au $750 \mathrm{~S}$ (red) 8

Au $585 \mathrm{~S}$ (pale yellow) 9

Au $585 \mathrm{~S}$ (yellow) 1

Au $585 \mathrm{~S}$ (red) 11

585/100 (pink) 13

$585 / 300$ (yellow) 15
990 Gold Titanium (yellow) 17 
9 carat

Au 375-Ag 100-Cu 450-Zn $75 \quad 375$ DF (yellow) $\quad 16$

* Similar alloy data have also been published in respect of 18 and 14 carat white gold alloys [18-22].

\section{The 990 ( 23.76 carat) Gold-Titanium Alloy}

\section{Metallurgical and Physical Properties}

In comparison with the metallurgy of the traditional $\mathrm{Au}-\mathrm{Ag}-\mathrm{Cu}$ and $\mathrm{Au}-\mathrm{Ag}-\mathrm{Cu}-\mathrm{Zn}$ carat gold alloys, that of $990 \mathrm{Au}-\mathrm{T}_{\mathrm{i}}$ is relatively simple. The phase diagram for the Au-Ti system was recently assessed by Murray [23] and the portion of it which is relevant, namely that for the composition range 85 to $100 \mathrm{wt} . \% \mathrm{Au}$ is presented in Figure 5. It will be seen that the solubility of $\mathrm{Ti}$ in solid gold falls steadily below the peritectic temperature of $1123^{\circ} \mathrm{C}$ as a result of the separation of TiAu4. Gafner [1] has reported the solubility as falling from $1.2 \mathrm{wt} . \%$ at $800{ }^{\circ} \mathrm{C}$ to $0.4 \mathrm{wt} . \%$ at $400{ }^{\circ} \mathrm{C}$. The $990 \mathrm{Au}-\mathrm{Ti}$ alloy (1 wt.\% Ti) therefore becomes solutionized at $800^{\circ} \mathrm{C}$, and on cooling from this temperature to $400{ }^{\circ} \mathrm{C}$ it hardens significantly, because of the relatively high volume of the compound (TiAu4) in which the $\mathrm{Ti}$ separates.

The behaviour of the alloy on solutionizing, cold working and age-hardening has been reported upon as well as the mechanical properties of the alloy on solutionizing and quenching, on cold working, and on age-hardening for different times at 400, 500 and $600{ }^{\circ} \mathrm{C}[1]$. These properties are comparable with the corresponding properties of conventional 14 and 18 carat coloured alloys in similar states. Of special interest is the fact that the 990 alloy retains enough ductility after hardening for rings fabricated from it to be adjusted in size. Moreover the cold worked alloy has a hardness of $120 \mathrm{HV}$, which is an ideal value for coins for striking. Coins and medallions can therefore be produced in this alloy without any annealing step between strip rolling and blanking.

Hardening for one hour at $500{ }^{\circ} \mathrm{C}$ gives the alloy a hardness of $240 \mathrm{HV}$ and a tensile strength of $740 \mathrm{MPa}$, which are comparable with the values for these proper- ties which are observed with conventional alloys hardened by high concentrations of copper. In this state the alloy has proved suitable for lathe turning using diamond tools for ring and bangle production. Grain size calls for the same attention in the $990 \mathrm{Au}$-Ti alloy as it does in conventional alloys, though no cases of orange peel effects associated with materials of large grain size have so far been observed. An alloy containing Au 990; Ti 9.1; Ru 0.5; and B $0.4 \%$ has been observed to yield castings of greatly improved texture. The 990 Au-Ti alloy exhibits a dramatic improvement in grain size following age-hardening of $70 \%$ deformed material at $500^{\circ} \mathrm{C}$. In respect of its physical properties and metallurgical behaviour this new alloy therefore presents few problems to those familiar with conventional coloured gold alloys. It does, however, have chemical properties which call for special attention.

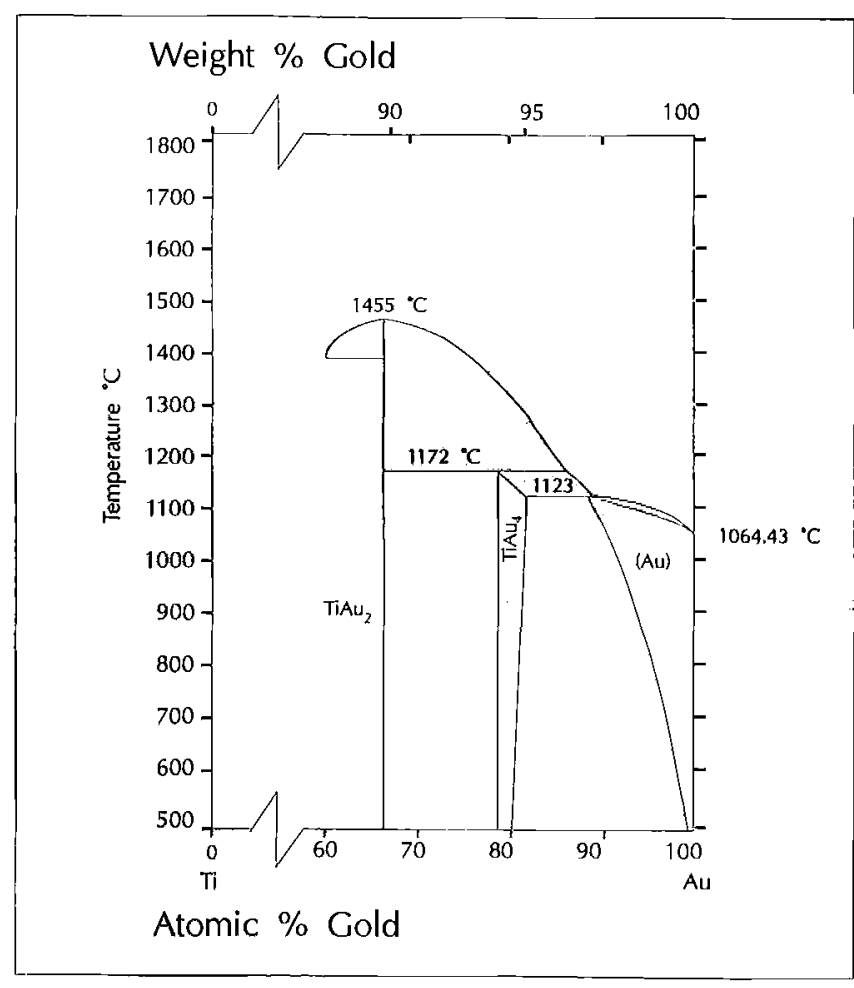

Figure 5

The assessed $A u$-Ti phase diagram for the composition range 85 to $100 \mathrm{wt} . \% \mathrm{Au}$. After [23]. 


\section{Chemical Properties}

Titanium reacts with both oxygen and nitrogen at elevated temperatures. As a result tarnish develops on the surface of the alloy when exposed to air under these conditions, and in the process titanium is lost from the alloy. As a result:

- Production of the alloy must be carried out in a vacuum in an induction furnace back-filled to at least 1 torr with pure argon.

- During procedures such as solutionizing, age-hardening, soldering and brazing, precautions must be taken to minimize its exposure to air. This can be done without recourse to vacuum equipment or protective atmospheres during most procedures. For example, solutionizing and heat treating can be carried out at the recommended temperatures of $800{ }^{\circ} \mathrm{C}$ and $500{ }^{\circ} \mathrm{C}$ respectively in molten salt baths. Similarly, the alloy can be protected during soldering and brazing by the use of fluxes. Not all salt baths or fluxes are suitable, however, since some attack the titanium in the alloy. Materials found suitable include $\mathrm{B}_{2} \mathrm{O}_{3}$ and Degussa 540 salt for solutionizing at $800{ }^{\circ} \mathrm{C}$, Degussa 430 salt and Fluxh for heat treating at $500{ }^{\circ} \mathrm{C}$, and Degussa Fluxes $-t$ or $-\mathrm{L}$ or Canning for soldering or brazing.

- The tarnish which forms on the alloy at elevated temperatures is different from that which develops on conventional alloys. It can be effectively removed by dipping the article into a $10 \%$ solution of potassium pyrosulphate $\left(\mathrm{K}_{2} \mathrm{~S}_{2} \mathrm{O}_{7}\right)$, drying, and then heating uncil the residual $\mathrm{K}_{2} \mathrm{~S}_{2} \mathrm{O}_{7}$ melts. On quenching and washing the alloy is obtained tarnish-free.

- Nor all crucible materials are suitable for use with the 990 alloy. Suitable materials are alumina, zirconia and high-purity carbon.

- Investment casting of the alloy can present problems. At present too few casting tests have been carried out for it to be classified as a casting alloy.

\section{Refining}

As a by-product of the search for suitable salts and fluxes for use with the alloy, it was found that Degussa salt 560 removes the titanium from the alloy when it is melted with it at $1100{ }^{\circ} \mathrm{C}$. Refining of scrap alloy to a fineness of 999.8 is achieved in 20 minutes at this temperature. This means that 990 Au-Ti scrap can be easily and rapidly refined to a state where it can be directly used for making a further batch of the alloy.

\section{References}

1 G. Gafner, Gold Bull., 1989, 22(4), 112-122

2 A.S. McDonald and G.H. Sistare, Gold Bull., 1978, $11(3), 66-73$

3 J. Leuser, Metall, 1949, 3, 105-10, 128

4 C. McCarl, R. Krahn and C. d'Antonio, Trans. Am. Inst., Min. Metall. Eng., 1969, 245, 432-45

5 Aurum (English Edition), 1979, 1, 22-3

6 Ibid., 1980, 2, 15-8

7 Ibid., 1980, 3, 15-8

8 Ibid., 1981, 5, 20-39

9 Ibid., 1981, 6, 19-22

10 Ibid., 1981, 7, 19-22

11 Ibid., 1981, 8, 14-7

12 Ibid., 1982, 10, 18-21

13 Ibid., 1982, 12, 26-9

14 Ibid., 1982, 11, 26-9

15 Ibid., 1983, 14, 41-4

16 Ibid., 1985, 23, 49-52

17 Gold Bull,, in preparation

18 Aurum, (English Edition), 1980, 4, 19-22

19 Ibid., 1982, 9, 17-20

20 Ibid., 1983, 15, 22-5

21 Ibid., 1983, 16, 29-32

22 Ibid., 1984, 17, 53-6

23 J.L. Murray, in 'Phase Diagrams of Binary Gold Alloys', Ed. by H. Okamoto and T.B. Massalski, ASM International, Metals Park, Ohio, 1987, 306-11

24 K. Yasuda, Gold Bull., 1987, 20(4), 90-103

25 'Metals Handbook', 8th edition, vol. 8, American Society for Metals, Metals Park, Ohio, 1973 